\title{
Groundwater Chemical Anomaly before and after the Chi-Chi Earth- quake in Taiwan
}

\author{
Sheng-Rong Song ${ }^{1, *}$, Wei-Yi Ku ${ }^{1}$, Yaw-Lin Chen ${ }^{1}$, Y-Chieh Lin ${ }^{1}$, Chia-Mei Liu ${ }^{1}$, Li-Wei Kuo ${ }^{1}$, \\ Tsanyao, F. Yang ${ }^{1}$ and Huann-Jih Lo ${ }^{1}$
}

(Manuscript received 16 April 2003, in final form 27 May 2003)

\begin{abstract}
The Chi-Chi earthquake $\left(M_{L}=7.3\right.$ and $12 \mathrm{~km}$ focal depth) occurred on 21 September 1999 in central Taiwan resulting in deaths totaling over 2300. After the earthquake we collected commercialized bottled water (namely Chingjing water), pumped from wells at Puli, Nantou County, central Taiwan, about $10 \mathrm{~km}$ northeast of the epicenter of this earthquake. The anions, e.g., $\mathrm{Cl}, \mathrm{SO}_{4}{ }^{2-}$ and $\mathrm{NO}_{3}{ }_{3}^{-}$, of the bottled water prepared from $1 \mathrm{De}$ cember 1998 until after the shocks for duration of about two and a half years were analyzed.

The analytical data display that the concentrations of both sulfate and nitrate have increased steadily after March 1999, as compared to the constant level measured since December 1998. They reached an excess of 129.9 and $94.7 \%$ in April, then dropped in July 1999, and decreased to about 10 and $20 \%$ below the constant values, respectively, till after the earthquake. These precursory chemical changes may be attributed to the stress/straininduced pressure changes in the subsurface water systems, followed by limited precursory geochemical discharges generated by limited changes in the levels of the subsurface reservoirs, thus finally leading to the mixing of deeper aquifer. Then, the groundwater was diluted by the injection of surface water into the subsurface system. This result, therefore, confirms that groundwater chemistry is promising for monitoring earthquakes.
\end{abstract}

(Key words: Chi-Chi earthquake, Geochemistry, Bottled water, Precursor)

\section{INTRODUCTION}

A destructive earthquake, magnitude $M_{L}=7.3$, occurred in central Taiwan at 1:47 local time on 21 September 1999. It caused about an 80-90 km long surface rupture along the Chelungpu fault with the largest measured vertical offset reaching as high as 5-8 $\mathrm{m}$ (Chen et

\footnotetext{
${ }^{1}$ Institute of Geosciences, National Taiwan University, Taipei, Taiwan, ROC

${ }^{*}$ Corresponding author address. Prof. Sheng-Rong Song, Institute of Geosciences, National Taiwan University, 245 Choushan Road, Taipei, Taiwan, ROC; E-mail: srsong@ccms.ntu.edu.tw
} 
al. 2001). The epicenter of the earthquake was located at $120.82^{\circ} \mathrm{E}$ and $23.85^{\circ} \mathrm{N}$ with hypocenter depth around 5-10 km, about $15 \mathrm{~km}$ east of the surface trace of the thrust fault (Chung and Shin 1999; Ma et al. 1999; Kao and Chen 2000), near the town of Chi-Chi, in Nantou County of cenmal Taiwan. This event was the largest earthquake on the island over the past hundred years and caused about 2,400 deaths, 10,000 injuries and more than 100,000 houses to be destroyed. Numerous aftershocks, including an event of $M_{w}=6.8$, were distributed around the main shock in a large area of central Taiwan (Kao and Chen 2000).

Besides faulting, the most striking features associated with the earthquake were the changes in various properties of the groundwater and gases, sandy explosion and land subsidence. Large-scale land subsidence and sandy explosions occurred in the counties of Yuanlin, Taichung and Nantou that caused severe damages of houses and public constructions. The large changes of groundwater levels, ranging from 1.0 to 11.1 meters were observed at 157 out of 179 monitoring wells in the Choshui River alluvial fan, located in the aftershock regions in central Taiwan (Chia et al. 2001 ; Lee et al. 2002).

Detecting useful short-term precursors of earthquakes has long been an aim of geoscientists. Many kinds of precursor, including chemical and hydrological changes of subsurface fluids, were reported prior to large earthquakes in the past. Among them, gases involved in hydrothermal processes $\left(\mathrm{Rn}, \mathrm{He}, \mathrm{CO}_{2}, \mathrm{CH}_{4}, \mathrm{H}_{2}, \mathrm{Ar}\right.$ and $\left.\mathrm{N}_{2}\right)$ and water chemistry $\left(\mathrm{Cl}^{-}, \mathrm{F}^{-}, \mathrm{NO}_{3}^{-}\right.$and $\mathrm{SO}_{4}^{-2}$ ) have been the most unambiguous precursory changes noted (Hauksson 1981; King 1986; Sugisaki et al. 1996; Tsunogai and Wakita 1995, 1996; Toutain et al. 1997). These geochemical anomalies are generally related to changes in the groundwater circulating system by the processes of earthquake generation (Thomas 1988; Sugisaki et al. 1996). Monitoring data on cations and anions in groundwater provide useful information for earthquake prediction in seismic countries (e.g., Koizumi et al. 1985; Barsukov et al. 1984/1985; Guiru et al. 1984/1985). Anomalies of ions in commercialized bottled groundwater and spring waters have also been recently detected to precede the major 1995 Kobe earthquake $\left(M_{L}=7.2\right)$ and 1996 Pyrenean earthquake $\left(M_{L}=5.2\right)$, respectively (Tsunogai and Wakita 1995, 1996; Toutain et al. 1997).

In this paper, we present the results of a similar study performed on bottled waters near the Chi-Chi earthquake area. Following local oral reports in the Puli town claiming that sudden disappearances of the surface water in the outlets of springs and local river occurred several to tens of days before the earthquake, we performed a geochemical study on the bottled mineral waters prepared several months before to two years after the earthquake.

\section{SAMPLE COLLECTION AND ANALYSIS}

Right after the Chi-Chi earthquake, we immediately started collecting the commercialized bottled waters in the markets, which are made by the groundwater of Puli, near the epicenter, about $15 \mathrm{~km}$ to the northeast in the aftershock regions (Fig. 1), in order to investigate possible precursory changes in groundwater. Puli's groundwater is famous as high-quality groundwater, which is mainly used in the brewing of wines and as drinking waters. The groundwater was pumped from a $50 \mathrm{~m}$-deep well and filtrated through natural pure-quartz sands and micro- 


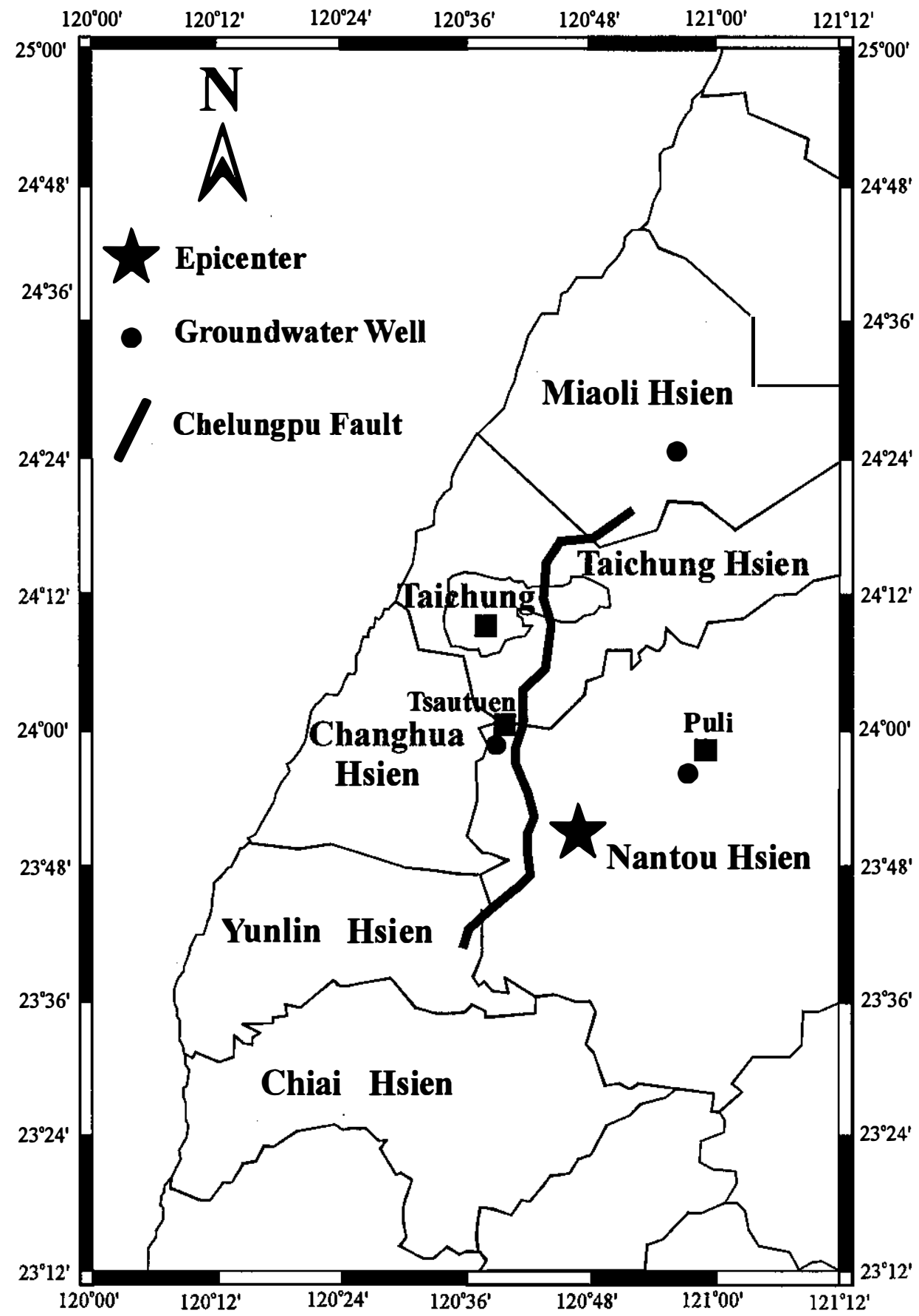

Fig. 1. Regional map of west-central Taiwan shows the surface rupture and the location of epicenter in the 21 September 1999 Chi-Chi earthquake and the sampling location of groundwater well. 
filters $(0.2 \mu \mathrm{m})$. After disinfecting by chlorine and ozone gases, the waters were sealed in polyethylene terephthalate bottles and distributed to the market as drinking water. The $\mathrm{pH}$ is $\sim 7.2$ and the chemical composition is chloride $(\sim 0.6 \mathrm{ppm})$, sulfate $(\sim 2.6 \mathrm{ppm})$, nitrate $(\sim 5.8$ $\mathrm{ppm})$ and fluoride $(\sim 0.22 \mathrm{ppm})$. This bottled water has the merit of providing groundwater samples with known pumping dates.

We collected over 120 bottles of drinking water with different dates ranging from $1 \mathrm{De}-$ cember 1998 to 20 September 1999, before the earthquake. The longest storage period before analysis was 260 days. The distribution of the bottled water was interrupted for about 15 days due to the earthquake disaster and disruption of normal life. After the restoration in distribution of the bottled water, we continuously collected about 140 bottled waters for two years after the earthquake and also collected the groundwater for comparison. In addition, we have 20 sets of duplicate water samples of the same date to examine the homogeneity of the water chemistry. We also collected groundwater at different depths in the Puli basin for chemical comparison between different aquifers. This study also tried to collect commercialized bottled water and groundwater prepared by other companies at different localities, e.g., Miaoli and Tsaotwen. Unfortunately, the groundwater from these companies is to make pure water. They removed most of the mineral elements in the groundwater, so the groundwater can't be used as tracer to investigate the precursors of the Chi-Chi earthquake.

Dissolved anions in samples were measured with an ion chromatograph (IC, Type Dionex DX-100). We measured the same water sample (as a running standard) after each sample analysis in order to enhance precision of the measurement. Analytical uncertainties in the absolute concentrations were less than $3 \%$ for all of the ions.

\section{RESULTS AND DISCUSSIONS}

\subsection{Temporal Variations in the Sulfate and Nitrate Concentrations}

As shown in Table 1, the differences of sulfate and nitrate concentrations in the same-day groundwater and bottled water are less than $10 \%$. These results imply that the anion concentration changes occurred in the filtrating and bottling processes are small. But the chloride concentration change that occurred in filtrating and bottling processes is very large due to disinfecting by chlorine gases. However, the trend of chloride change is similar to that of sulfate and nitrate. Table 2 shows that the chloride, sulfate and nitrate concentrations increase with the depth of pumping from different layers of groundwater in the Puli basin, i.e., concentrations of these anions increase with the depth.

The temporal variations in the $\mathrm{SO}_{4}{ }^{2-}$ and $\mathrm{NO}_{3}{ }^{-}$concentrations of the bottled water samples from the Puli groundwater from December 1998 to May 2001 are shown in Figs. 2a, b, respectively. The nitrate is the major anion in the groundwater and its average concentration reaches $6.80 \mathrm{ppm}$, whereas that of the sulfate ion is about $2.94 \mathrm{ppm}$. Generally, the concentrations of sulfate in samples are almost constant, except for a few dates, but this is not the case for nitrates, which are more fluctuant. Two-sigma relative standard deviations $(2 \sigma)$ were calculated for those samples and are $29.3 \%$ for $\mathrm{SO}_{4}^{2-}$, and $57.1 \%$ for $\mathrm{NO}_{3}^{-}$, respectively. These 
Table 1. The $\mathrm{SO}_{4}^{2-}$ and $\mathrm{NO}_{3}^{-}$concentrations of the groundwater and bottled water in the same day.

\begin{tabular}{|l|r|r|r|r|}
\hline & \multicolumn{2}{|c|}{$\mathrm{SO}_{\mathbf{4}}{ }^{2-}$} & \multicolumn{2}{c|}{$\mathrm{NO}_{3}{ }^{-}$} \\
\hline & Groundwater & Bottled water & Groundwater & Bottled water \\
\hline $1999-10-04$ & 2.57 & 2.73 & 4.63 & 4.87 \\
\hline $1999-10-05$ & 2.56 & 2.71 & 4.40 & 4.52 \\
\hline $1999-10-06$ & 2.62 & 2.65 & 4.45 & 4.73 \\
\hline $1999-10-07$ & 2.48 & 2.66 & 4.31 & 4.69 \\
\hline $1999-10-08$ & 2.42 & 2.67 & 4.53 & 4.84 \\
\hline $1999-10-09$ & 2.48 & 2.40 & 4.76 & 5.12 \\
\hline
\end{tabular}

Table 2. The $\mathrm{SO}_{4}{ }^{2-}, \mathrm{NO}_{3}$ and $\mathrm{Cl}^{-}$concentrations of the groundwater from different pumping depth.

\begin{tabular}{|c|c|c|c|}
\hline Depth (m) & $\mathbf{S O}_{4}{ }^{2-}$ & $\mathbf{N O}_{3}{ }^{-}$ & $\mathrm{Cl}^{-}$ \\
\hline 20 & 2.44 & 4.17 & 0.56 \\
\hline 50 & 2.68 & 5.18 & 0.76 \\
\hline 120 & 40.05 & 10.85 & 9.91 \\
\hline
\end{tabular}


$2 \sigma$ domains can be considered as representative values for the groundwater background. They may be attributed to annual fluctuations in groundwater chemistry, which themselves result from rainfall and other superficial phenomena, heterogeneity in the sampling and analytical uncertainties (Toutain et al. 1997). Except for the sulfate and nitrate ions, all cations and anions vary within the $2 \sigma$ domains during the entire sampling period. Fig. 2a shows that the $\mathrm{SO}_{4}^{2-}$ concentrations increased steadily after March 1999 as compared to the constant level measured since December 1998 and reached the maximum value $(6.76 \mathrm{ppm})$ in the mid-April of 1999 , which was about $129.9 \%$ above the mean value; they then decreased slowly to the minimum after the earthquake occurred, although a few perturbations occurred in June and July of 1999. Nitrate contents also increased steadily after March of 1999 as compared to the constant level since December of 1999, but two peaks occurred in April and June of 1999 with the concentrations reaching the maximum values, $12.7 \mathrm{ppm}$ and $13.2 \mathrm{ppm}$, respectively, which are about 86.9 and $94.7 \%$ above the mean value. Then, the concentration decreased slowly to the minimum ( $2.87 \mathrm{ppm}$ ) about $60 \%$ below the mean value two months after the earthquake occurred (Fig. 2b).

\subsection{Mechanism Causing the Chemical Changes}

The observed temporal $\mathrm{SO}_{4}^{2-}$ and $\mathrm{NO}_{3}^{-}$variations cannot be attributed to storage conditions, including dissolution and/or absorption processes or evaporation of water in the bottles according to the data of pumping dates. Changes in the chemical compositions of groundwater previously were attributed to several factors, including different compositions of groundwater recharge, the petrologic and mineralogical compositions of subsurface rocks, water-rock interactions (Domenico and Schwartz 1990; Langmuir 1997), the mixing of different water compositions and artificial pollutants. The sulfate ion is not stable under groundwater conditions, and can be changed by sulfide mineral oxidation, the precipitation-dissolution of gypsum in an unsaturated zone, the dissolution of anhydrite or gypsum or by redox reactions in a saturated zone (Domenico and Schwartz 1990). The nitrate ion is more stable than sulfate, but it also can be changed by redox reactions (Domenico and Schwartz 1990). Such reactions, however, are not quick enough to cause such sudden changes in $\mathrm{SO}_{4}{ }^{2-}$ and $\mathrm{NO}_{3}{ }^{-}$concentrations, as shown in Fig. 2 in a stable subsurface water system. In addition, the changes may occur at any time. However, they just occurred once during about two and a half years monitoring period. Among all of the factors capable of causing the observed temporal variations of both $\mathrm{SO}_{4}{ }^{2-}$ and $\mathrm{NO}_{3}{ }^{-}$ concentrations in a short duration (Fig. 2), the mixing of different water compositions (King et al. 1981; Thomas 1988) and artificial pollutants are the only two that cannot be ruled out.

Puli is located in a highly polluted, industry-free and lightly populated mountainous basin. It is clear that pollutant solutes require media, i.e., meteoric water, in order to be transported down into the groundwater system. However, no correlations between the increases of the ions and the daily amounts of precipitation were found during the sampling period (Fig. 2), suggesting that the observed temporal variations in the $\mathrm{SO}_{4}{ }^{2-}$ and $\mathrm{NO}_{3}{ }^{-}$concentrations were not induced by recent meteoric water flowing down into the circulation system of the subsurface water system. Accordingly, the abrupt change in the temporal variations in the $\mathrm{SO}_{4}^{2-}$ and $\mathrm{NO}_{3}{ }^{-}$ concentrations cannot be attributed to artifact pollutants. It follows that the most probable 


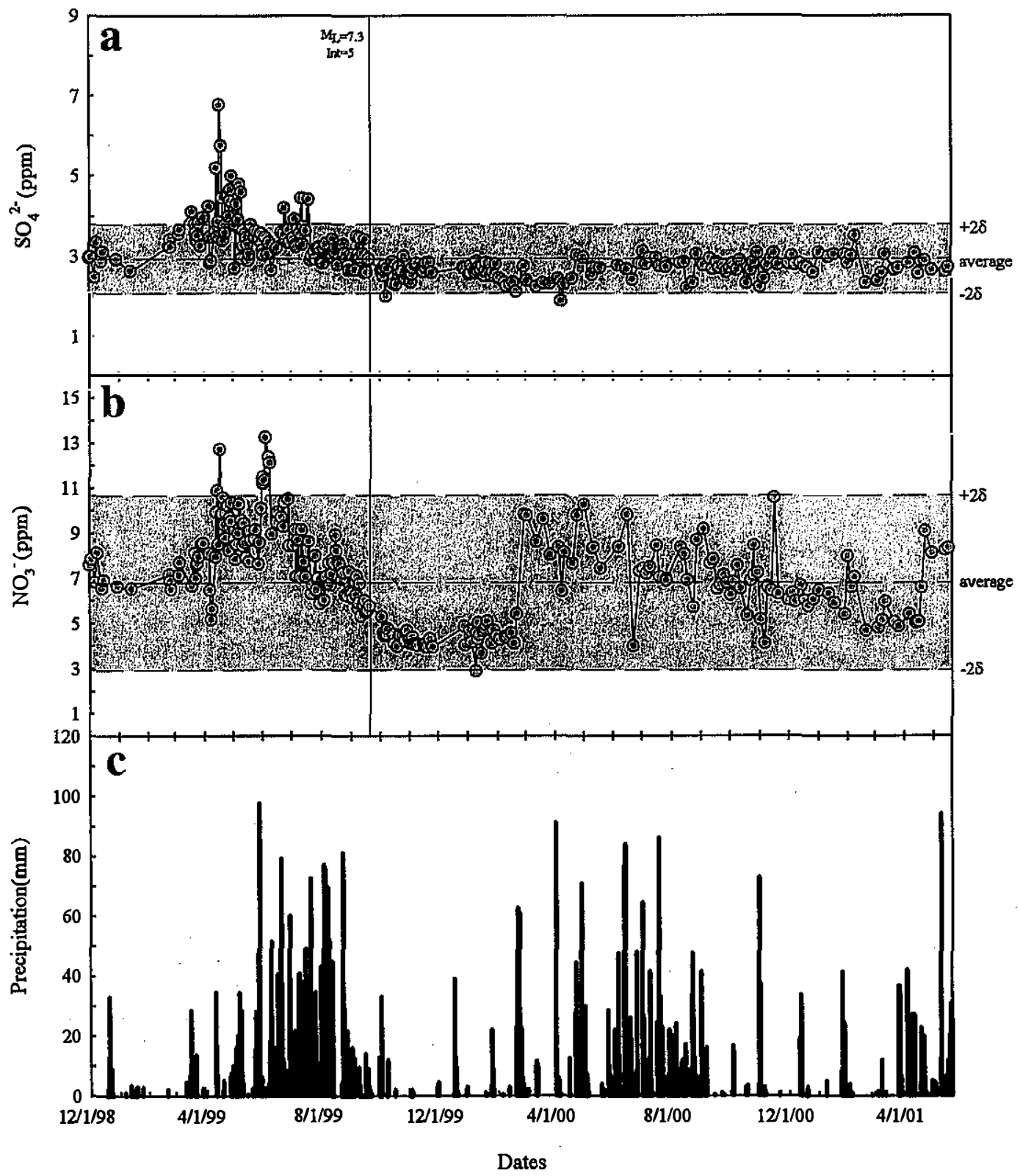

Fig. 2. Temporal variations in (a) $\mathrm{SO}_{4}{ }^{2-}$ and (b) $\mathrm{NO}_{3}{ }^{-}$concentrations in the Puli groundwater. The average concentration (solid lines) and $2 \sigma$ variation range (dashed lines) are also shown. The vertical line represents tbe date of Chi-Chi earthquakes. (c). Daily amounts of precipitation obtained in the Puli area (Data from Central Weather Bureau of Taiwan). 
factor controlling the temporal chemical variations in the groundwater of the Puli area is the mixing of water bodies with different compositions.

What is particularly salient is that such chemical changes are quick and drop to the minimum at the time, which correlates well with the Chi-Chi earthquakes (Fig. 2). Thus, it is reasonable to attribute the mechanism of the rapid temporal chemical variations in the groundwater from the Puli basin to the mixing of different aquifers or reservoirs. It is equally justifiable to make the claim that the mechanism causing the rapid temporal chemical variations may be related to the earthquake. Such an interpretation is strongly supported by the observation of the large 1.0- to 11.1-m changes in the groundwater levels induced by the Chi-Chi earthquake on 21 September 1999, as recorded at 157 out of 179 monitoring wells in the Choshui River alluvial fan, which is located about $10 \mathrm{~km}$ west of the Chelungpu fault (Chia et al. 2001; Lee et al. 2002).

Two different earthquake-induced mechanisms for the mixing of different water systems of different compositions have been proposed: permeability enhancement due to a breaking in the crust (King et al. 1981; Thomas 1988; Rojstaczer and Wolf 1992; Rojstaczer et al. 1995), and changing pressure in aquifer systems because of elastic compression (Muir-Wood and King 1993; Toutain et al. 1997), before and after a major earthquake. The former necessitates cracking water barriers and would require large-scale mixing processes (Tsunogai and Wakita 1996) to induce the mixing of initially isolated aquifers. The chemical variations of Puli groundwater are characterized by the short-term reversible anomalies, since the sulfate and nitrate ion contents returned to pre-seismic levels within a few days of the onset of the anomaly. Therefore, the permeability enhancement mechanism is an implausible explanation of the chemical changes that occurred in Puli groundwater.

The other mechanism is induced by elastic compression on aquifers to generate pressure variations among themselves, which in turn may generate reversible changes in hydraulic levels (Muir-Wood and King 1993) and, therefore, lead to subsequent limited geochemical discharge effects (Thomas 1988). The observed rapid chemical changes in the Puli groundwater (Fig. 2) imply that a limited mixing of aquifers with different compositions occurred. Therefore, we suggest that this mechanism can be used to explain the $\mathrm{SO}_{4}{ }^{2-}$ and $\mathrm{NO}_{3}$ - concentration changes before and after the earthquake. Aside from this, the mechanism is also supported by the significant changes in groundwater levels induced by the Chi-Chi earthquake (Chia et al. 2001; Lee et al. 2002) and the increase of sulfate and nitrate concentrations with depth (Table 2). It is most lightly expected that the sulfate- and nitrate-rich waters were introduced into the Puli groundwater from a deeper aquifer. However, the ion concentrations gradually decreased after June of 1999 due to the injection of surface water with lower sulfate and nitrate concentrations into the subsurface water system, as supported by the local oral reports in the Puli town claiming that sudden disappearances of the surface water in the outlets of springs and local river occurred several to tens of days before the earthquake.

\section{CONCLUSIONS}

A short-term, reversible precursory geochemical anomaly has been recorded in the groundwater prior and subsequent to the Chi-Chi earthquake in the Puli basin in central Taiwan. The 
chemical anomalies were sharp and sudden increases in sulfate and nitrate ions, which gradually decreased until the earthquake occurred. These are interpreted here as stress/strain-induced pressure changes in subsurface water systems, followed by limited precursory geochemical discharges generated by limited changes in the levels of the subsurface reservoirs, thus finally leading to the mixing of deeper aquifer. Then, the groundwater was diluted by the injection of the surface water into the subsurface system. This strongly suggests that the groundwaters in the Puli basin may be useful for recording strain changes and that they may serve well in earthquake precursor research.

Acknowledgements The authors would like to thank the company manufacturing mineral waters for providing the samples and the assistance of $\mathrm{Mr}$. Yu, W. Y. for partial IC and ICPAES analyses. Thanks are also due to two anonymous referees whose suggestions and valuable reviews greatly improved the manuscript. This research was supported by the National Science Council, Republic of China under grants NSC 89-2116-M-002-046 and partly by the Central Geological Survey, Ministry of Economic Affairs.

\section{REFERENCES}

Barsukov, V. L., G. M. Varshal, and N. S. Zamokina, 1984/1985: Recent results of hydrogeochemical studies for earthquake prediction in the USSR. Pure Appl. Geophys. , 122, 143-156.

Chen, Y. G., W. S. Chen, J. C. Lee, Y. H. Lee, C. T. Lee, H. C. Chang, and C. H. Lo, 2001: Surface rupture of the 1999 Chi-Chi earthquake yields insights on the active tectonics of central Taiwan. Bull. Seismo. Soc. Amer., 91, 977-985.

Chia, Y. P., Y. S. Wang, J. J. Chiu, and C. W. Liu, 2001: Changes of groundwater level due to 1999 Chi-Chi earthquake in the Choushui River alluvial fan in Taiwan. Bull. Seismol. Soc. Amer., 91, 1062-1068.

Chung, J. K., and T. C. Shin, 1999: Implication of the rupture process from the displacement distribution of strong ground motions recorded during the 21 September 1999 Chi-Chi Taiwan earthquake. TAO, 10, 777-786.

Domenico, P. A. and F. W. Schwartz, 1990: Physical and Chemical Hydrogeology. John Wiley \& Sons, Singapore. 560p.

Guiru, L., W. Fongliang, W. Jihua, and Z. Peiren, 1984/1985: Preliminary results of seismogeochemical research in China. Pure Appl. Geophys., 122, 218-230.

Hauksson, E., 1981: Radon content of groundwater as an earthquake precursor: evaluation of worldwide data and physical basis. J. Geophys. Res., 86, 9397-9410.

Kao, H., and W. P. Chen, 2000: The Chi-Chi earthquake sequence: active out-of-sequence thrust faulting in Taiwan. Science, 288, 2346-2349.

King, C. Y., 1986: Gas geochemistry applied to earthquake prediction. An overview. J. Geophys. Res., 91, 12269-12281.

King, C. Y., W. C. Evans, T. Presser, and R. Husk, 1981: Anomalous chemical changes in well waters and possible relation to earthquakes. Geophys. Res. Lett., 8, 425-428. 
Koizumi, N., R. Yoshioka, and Y. Kishimoto, 1985: Earthquake prediction by means of change of chemical composition in mineral spring water. Geophys. Res. Lett., 12, 510-513.

Langmuir, D., 1997: Aqueous Environmental Geochemistry. Prentice-Hall, New Jersey ,460p.

Lee, M., T. K. Liu, K. F. Ma, and Y. M. Chang, 2002: Coseismic hydrological changes associated with dislocation of the September 21, 1999 ChiChi earthquake, Taiwan. Geophy. Res. Lett., 29, 1824-1828.

Ma, K. F., C. T. Lee, Y. B. Tsai, T. C. Shin, and J. Mori, 1999: The Chi-Chi Taiwan earthquake: large surface displacement on an island thrust fault. EOS, 80, 605-611.

Muir-Wood, R. and G. C. P. King, 1993: Hydrological signatures of earthquake strain. $J$. Geophys. Res., 98, 22035-22068.

Rojstaczer, S., and S. Wolf, 1992: Permeability changes associated with large earthquakes: an example from Loma Prieta, Califomia. Geology, 20, 211-214.

Rojstaczer, S., S. Wolf, and R. Michel, 1995: Permeability enhancement in the shallow crust as a cause of earthquake-induced hydrological changes. Nature, 373, 237-239.

Sugisaki, R., K. Ito, K. Nagamine, and I. Kawabe, 1996: Gas geochemical changes at mineral springs associated with the 1995 southern Hyogo earthquake (M=7.2), Japan. Earth Planet. Sci. Lett., 139, 239-249.

Thomas, D., 1988: Geochemical precursors to seismic activity. Pure and Appl. Geophys., 126, 241-265.

Toutain, J. P., M. Munoz, F. Poitrasson, and A. C. Lienard, 1997: Springwater chloride ion anomaly prior to a $\mathrm{M}_{\mathrm{L}}=5.2$ Pyrenean earthquake. Earth Planet. Sci. Lett., 149, 113-119.

Tsunogai, U., and H. Wakita, 1995: Precursory chemical changes in ground water: Kobe earthquake. Japan. Science, 269, 61-63.

Tsunogai, U., and H. Wakita, 1996: Anomalous change in groundwater chemistry-possible precursors of the 1995 Hyogo-ken Nanbu Earthquake, Japan. J. Phys. Earth, 44, 381390. 